Hernández, David. Reformulando la revolución cubana. La presidencia de Raúl Castro (20082013)

\title{
REFORMULANDO LA REVOLUCIÓN CUBANA. LA PRESIDENCIA DE RÁUL CASTRO (2008-2013)
}

\author{
RETHINKING THE CUBAN REVOLUTION. \\ RAÚL CASTRO'S PRESIDENCY (2008-2013)
}

\author{
DAVID HERNÁNDEZ \\ Universidad Complutense de Madrid \\ davidhm26391@gmail.com
}

Fecha de recepción: febrero de 2015 Fecha de aceptación: diciembre de 2015

\section{RESUMEN}

En el presente trabajo, analizamos la presidencia de Raúl Castro, tras la ausencia en el poder de su hermano Fidel Castro. Los años de gobierno del nuevo presidente han estado marcados por una serie de reformas profundas, que han alterado la dinámica política y económica de la isla. El régimen cubano vive tiempos convulsos, donde el estado intenta responder a los cambios internacionales y la transformación de la sociedad cubana, sin alterar los principios básicos de la revolución de 1959. Sin duda alguna, el mandato de Raúl Castro está marcando el presente y futuro del país caribeño.

PALABRAS CLAVE: reformas, régimen cubano, Raúl Castro, estado socialista

\begin{abstract}
In the present dissertation, we analyze the presidency of Raúl Castro, after his brother Fidel Castro left power. The years of government of the new president have been marked by a series of deep reforms that have altered the political and economic dynamics of the island. The Cuban regime lives turbulent times, where the state tries to respond to international changes and transformation of Cuban society, without altering the basic principles of the 1959 revolution. Certainly, Raul Castro's mandate is marking the present and future of the Caribbean country.
\end{abstract}

KEY WORDS: reforms, cuban regime, Raúl Castro, socialist state.

JEL: P20, P30, Y80, Z19,

\section{LA HERENCIA DE FIDEL CASTRO}

Líder de la revolución de 1959, Fidel Alejandro Castro Ruz sería oficialmente reconocido como Presidente de la República de Cuba tras el plebiscito constitucional de febrero de 1976 (Rivero, 2013: 11), donde la constitución primigenia de 1940 fue reescrita en 60 de sus 141 artículos, adquiriendo sobre base constitucional el rasgo comunista típico del régimen. No obstante, ya desde el gobierno provisional de Manuel Urrutia, donde ocupó el cargo de Comandante en Jefe de las Fuerzas Armadas, y posteriormente bajo la presidencia de su amigo Osvaldo Dorticós, siendo 
Hernández, David. Reformulando la revolución cubana. La presidencia de Raúl Castro (20082013)

Primer Ministro; Fidel fue reconocido tanto por el pueblo cubano, actores internacionales y miembros de la vida política y militar isleña, como el auténtico líder del país.

De todo ello se sirvió al que pronto se le denominó bajo el apelativo del Líder Máximo (Skierka, 2007:118), para marcar la deriva del nuevo estado que surgía tras el derrocamiento del Coronel Fulgencio Batista, copando el poder de facto desde la entrada triunfal el 8 de enero de 1959 en La Habana. Es innegable que tras el compromiso de implementar el ambicioso programa socialista diseñado en julio de 1956 (Balfour, 2009: 62-63), reformulado durante los sesenta bajo lemas tercermundistas postcoloniales, y las décadas de los setenta y ochenta por influencias soviéticas; todas las medidas emprendidas han contado siempre con el beneplácito e impulso último del estadista, otorgándole un cariz legitimador.

En esta misma línea de argumentación, hemos asistido a una forma de gobierno con un fuerte carácter personalista, convirtiendo su actividad política, a las miradas de muchos, en un proyecto propio e individualista (Gratius, 2008a: 1-2). Por supuesto, el conglomerado legislativo constituido a lo largo de más de cincuenta años de régimen no ha dependido directamente del intelecto del expresidente, no obstante, las normas más relativas y el proyecto máxime ideológico si han pasado por su supervisión. A este respecto, siempre ha existido la duda sobre hasta qué punto llegaba la omnipresencia del Líder en todas las agendas ministeriales, si poseían autonomía en sus decisiones el resto de miembros del gobierno, incluido su propio hermano menor.

Con todo ello, no requiere extendernos más sobre la figura de Fidel Castro, la cuestión es aprehender de forma directa la situación nacional que Raúl asume tras su nombramiento, aunque bien es cierto que, el actual Presidente del Consejo de Estado ha sido la mano derecha de su hermano a lo largo de su extenso mandato con altos puestos de responsabilidad, por lo que la realidad patria no le sería ajena.

El arquetipo político cubano se fundamenta en una Asamblea Nacional del Poder Popular con potestad constituyente y legislativa. Sus representantes son elegidos por voto directo en Asambleas Municipales, por el plazo de cinco años. Dichas instituciones locales emergen como el órgano más importante de relación entre el partido y la ciudadanía, donde supuestamente se incentiva la participación libre de la sociedad. Igualmente, las labores conjuntas de la Asamblea Nacional se limitan a episodios bianuales para ratificar decisiones gubernamentales.

Entre sus diputados se elige a los miembros del Consejo de Estado, constituido por un Presidente, quien debe anunciar para su aprobación a su segundo, el Primer Vicepresidente, también los cincos Vicepresidentes y el resto de miembros gubernamentales, que constituyen diversas secretarías (ICEX, 2012: 4-5). El Consejo es el órgano político más importante del sistema, siendo verdaderamente el dispuesto para legislar, además con las respectivas capacidades ejecutivas y judiciales. Así, cuando el 31 de julio de 2006 el secretario personal de Fidel, Carlos Valenciaga, anuncia a los medios que el Presidente delegaba de sus funciones provisionalmente por convalecencia quirúrgica, por entonces, el PrimerVicepresidente del Consejo de Estado, Raúl Castro, tomaba las riendas del ejecutivo 
Hernández, David. Reformulando la revolución cubana. La presidencia de Raúl Castro (20082013)

hasta la próxima Asamblea Nacional del Poder Popular prevista para dos años después.

La coyuntura económica cubana a inicios del siglo $X X$ era verdaderamente calamitosa, tras la caída de la URSS a principios de los noventa, el régimen castrista perdía su principal apoyo de financiación foránea. La profunda crisis que abatió la isla, aunado al cerco que mantiene su vecino norteño, llevo a las voces más apocalípticas a vaticinar el fin de otro sistema comunista (Dilla Alfonso, 2008). Sin embargo, las reformas económicas emprendidas en los subsiguientes años noventa, junto al apoyo recibido de aliados como China y Venezuela, al igual que el de países regionales y la permisividad de la Unión Europea, permitió una lenta recuperación, acelerada en el primer lustro del nuevo milenio. Como reflejan numerosas estadísticas internacionales, se estima que la economía cubana tuvo un considerable ritmo de crecimiento en los primeros lustros del siglo XXI, aunque no es menos correcto que dicho progreso partía de unos índices muy inferiores.

Empero, los ya habituales problemas macroeconómicos siguen vigentes durante el nuevo mandato, pues ni las reformas han conseguido resolver cuestiones enquistadas, ya sea la elevada dependencia de las importaciones de alimentos, resultado de décadas de políticas agrarias erradas; igualmente, la incesante sujeción a productos extranjeros intermedios motivados por una mayor demanda interna inducida gracias al ascenso de las rentas per cápita (Amor, 2010: 97-99). A este respecto, los ingresos de la población constituyen el significado último de esa subida importante, ya que la evolución de los ingresos nominales llevaban mostrando una tendencia al crecimiento, que se explica por los incrementos salariales a ciertos sectores que dependen del presupuesto estatal, además de la mejora de algunas actividades productivas y el ingreso de remesas, entre otros factores.

En definitiva, en el último mandato activo de Fidel la economía cubana alcanzo ciertos logros considerables, destacando un incremento de la producción de petróleo y gas gracias al inicio de intercambios tecnológicos con China y Venezuela, aún más, con los convenios petroleros firmados con el gobierno aliado chavista han proporcionado un alivio considerable a los balances estatales, frenando la espiral inflacionaria de los primeros años de siglo (Garrido, 2009: 132). Estrechamente vinculado, la cuenta corriente de la balanza de pagos, históricamente deficitaria en Cuba, comenzó a conocer índices superávit a partir de 2004, esto sería consecuencia primordialmente del incremento de las exportaciones de servicios profesionales y de las remesas.

Por otra parte, desde los ochenta el turismo europeo supuso un importante bálsamo para las maltrechas arcas cubanas, convirtiéndose en el principal sector de ingresos y generador de empleo por iniciativa privada. Mas, la especialización en el sector servicios justificado por la demanda de profesionales y tecnologías sanitarios desde Venezuela y otros países latinoamericanos, ha llevado importantes crecimientos del PIB y suplir ciertos déficit comerciales. De manera que, aproximadamente el último trienio en el poder del líder comunista (2003-2006) estuvo claramente señalada por una inclinación positiva de la economía caribeña, sin conseguir corregir las carencias y desigualdades adheridas al propio modelo. 
Hernández, David. Reformulando la revolución cubana. La presidencia de Raúl Castro (20082013)

Al respecto de la relación social y el sistema político, la entrada a la presidencia interina de Raúl Castro coincidió con los procesos judiciales abiertos tras la Primavera Negra que conmocionaron a la opinión pública cubana y comunidad internacional. Entonces, setenta y cinco disidentes, la mayoría de ellos médicos y periodistas, fueron arrestados y sometidos a juicios sumarios a la razón de actuar contra la estabilidad económica y social del país. Estos sucesos tuvieron una importante respuesta social, en las Damas de Blanco, constituyendo un movimiento activamente vigente y que ha alcanzado una enorme repercusión mediática.

Desde este momento, la disidencia cubana y la oposición al régimen han alcanzado una resonancia internacional, condicionando muchos de los comportamientos de agentes externos con el gobierno comunista. Sin embargo, como denuncian algunas organizaciones, la represión política no se vio frenada con la llegada al poder de Raúl Castro (Rico, 2009). Las tensiones políticas y sociales han estado presentes en casi toda la vida del régimen castrista, pero nunca antes, debido al avance de las tecnologías de la comunicación, se ha visualizado y constatado tan claramente las fracturas entre la sociedad civil y el aparato del partido único del gobierno.

En otro ámbito más alejado, sobre los antecedentes relativos a la política exterior, debemos señalar que las relaciones del último gobierno de Fidel Castro, continuaron estando condicionados por las disensiones con Washington, donde la administración Bush marco una línea política más agresiva que gobiernos anteriores. Las intenciones estadounidenses buscaron propiciar una transición dentro de la isla para alcanzar en fin último un modelo democrático y liberal, a través de la Comisión de Ayuda para Cuba Libre se diseñó un ambicioso plan de actuación (Alzugaray, 2012:144-145). Dicho proyecto focalizo mayormente sus esfuerzos en aumentar la financiación de los grupos opositores, además de favorecer los mecanismos de comunicación entre disidentes y difundiendo propaganda crítica a la población.

Sin embargo, las pretensiones del establishment americano se vieron menguadas por una corriente alternativa. En la región latinoamericana comenzó una actitud mucho más conciliadora con la autoridad cubana, alimentado por la diversificación de procesos de integración regional y amistades en naciones líderes tan dispares como Argentina, Brasil y México (Serbín, 2012: 200-201). Por otra parte, desde otros actores de la categoría de la Unión Europea también se patrocinó una actitud más benevolente, debido en parte al profundo cambio marcado por la política hacia la isla del gobierno español, aunque se siguió haciendo hincapié en los derechos humanos. Igualmente, las aspiraciones expansionistas de la potencia emergente china, sirvieron a las intenciones de la diplomacia castristas para ampliar los márgenes de actuación en la sociedad internacional. Pekín encontró un valioso aliado frente a las costas de Florida. Por lo tanto, podemos afirmar que actualmente se dibuja un medio global más propicio para el régimen, en comparación con décadas anteriores.

\section{RAÚL CASTRO, LA SOMBRA ALARGADA DE UN HERMANO}

Raúl Castro, ochenta y tres años, es uno de los jefes de estado de mayor edad de la actual sociedad internacional. El hermano mediano de los hijos del matrimonio entre el español Ángel Castro y la cubana de descendencia canaria Lina Ruz, nacido el 3 de junio de 1931 en Birán, desenvolvió su infancia y adolescencia a la sombra de sus hermanos mayores (Montaner, 2009); entre ellos Fidel, cinco años mayor, se 
Hernández, David. Reformulando la revolución cubana. La presidencia de Raúl Castro (20082013)

convertiría en uno de los grandes referentes a lo largo de su vida. Con una escolarización marcada por los cánones jesuitas, no sería hasta su experiencia universitaria en La Habana, cuando verdaderamente comenzaron sus inquietudes políticas que le llevarían a abrazar rápidamente los ideales comunistas.

En 1949, motivado por los relatos de su idolatrado hermano, se traslada a la ciudad costera para estudiar en el Instituto de Administración Pública; por entonces, Fidel ya tenía una azarosa vida estudiantil, miembro de la Federación de Estudiantes Universitarios y afiliado al Partido Ortodoxo fundado por Eduardo Chibás, un político carismático entre los jóvenes debido a su discurso reformista y crítico con las corruptelas, influyó enormemente en las primigenias concepciones políticas de Fidel Castro (Balfour, 2009: 47). Sin embargo, en las connotaciones políticas juveniles de los dos hermanos, se apreciaran las primeras divergencias ideológicas (Botín, 2010: 50-54). Mientras el futuro presidente de Cuba, optaba inicialmente por un discurso moderado con rasgos nacionalistas, Raúl pronto se encamino por el sendero comunista al ingresar y ser miembro significativo de las Juventudes Socialistas, pertenecientes al Partido Comunista Cubano. En un primer momento, esta situación género una cierta desazón entre los dos hermanos, ya que el pequeño de ellos parecía presentar un discurso más radical que el mayor.

Tras la llegada al poder del militar Fulgencio Batista, Fidel Castro inició el camino revolucionario que serviría de embrión para el Movimiento 26 de Julio, no obstante Raúl se mostró mucho más reacio en dichas pretensiones, siguiendo el discurso de la línea comunista de por entonces, reticente a la confrontación directa contra el régimen. Empero, tras el viaje por los países de la Europa del Este en 1953, conjugado a un recrudecimiento del régimen hacia las fuerzas opositoras, Raúl decidió integrarse a los operativos de Fidel para una maniobra armada (Botín, 2010: 59-60). El fracasado intento de asalto al cuartel de Moncada, el posterior proceso de encarcelamiento, así como su obligado retiro a México; le llevaron junto al dirigente del M26 a reelaborar su propia ideología, inspirada en las ideas comunistas pero alejadas del inmovilismo de los opositores isleños. Su regreso a Cuba en 1956 y las operaciones guerrilleras iniciadas en Sierra Maestra realizadas bajo las órdenes de su hermano y la figura del Che Guevara, no cegarían el reconocimiento de su capacidad estratégica entre el resto de los compañeros.

Con la ascensión de los revolucionarios al poder en 1959, Raúl sería tempranamente nombrado Ministro de las Fuerzas Armadas Revolucionarias, cargo que ocuparía hasta 2008. Desde entonces, ha sido el hombre más relevante de las fuerzas nacionales de defensa, supervisando directamente el funcionamiento de los servicios de inteligencia o la policía secreta. Incluso, se le achaca ser el brazo inflexible que no ha tolerado ningún amago de discrepancia interna. Asimismo, ha sido visto como la ligazón entre el Partido Comunista y la cúpula militar (Gratius, 2008a). Siempre ha existido una corriente explicativa que propugnaba una mayor potestad decisoria del hermano menor en ciertos asuntos; ocupando reconocidamente y con todas sus virtudes la labor de mano derecha del presidente.

\section{LA SOCIEDAD CUBANA, NUEVAS NECESIDADES}

La población cubana no es la misma que abrazo los albores de la revolución cubana, son ya varias las generaciones que han nacido y crecido bajo la sombra del Gran 
Hernández, David. Reformulando la revolución cubana. La presidencia de Raúl Castro (20082013)

Líder, las mismas que no han conocido otro modelo social, político y económico. No hay lugar a la duda de que nos encontramos ante una nueva ciudadanía, con necesidades y demandas muy distintas a las del siglo pasado.

Dicho esto, paradójicamente nos encontramos ante una sociedad que se encuentra en un acelerado proceso de envejecimiento, siguiendo un modelo más típico de países desarrollados. Según estadísticas vertidas en el año 2012 por la Oficina Nacional, se estima que en torno al $18 \%$ de la población tiene más de sesenta años, lo que implica más de dos millones de cubanos en una población total cifrada en 11. 247. 925. Pero las previsiones oficiales van más allá, prediciendo un futuro demográfico bastante negativo, con la posibilidad de que en 2035 la población mayor de sesenta años llegue a superar los tres millones y medio. Estos resultados presentarían a Cuba como el país más envejecido de América Latina en la década de los treinta, y para mediados de siglo estaría entre los diez países más envejecidos del mundo (ONEI, 2012: tabla 3.1). Las consecuencias sociales son extremadamente preocupantes, ya que Cuba se enfrenta al reto de mantener un portentoso sistema de seguridad social, dentro de los condicionantes de una nación en vías de desarrollo, frente a una población cada vez más envejecida. Además, no hay que desdeñar los flujos migratorios, principalmente protagonizados por el capital humano más joven que posee la isla, lo que debilita sus posibilidades de crecimiento demográfico.

Por otra parte, centrados en aspectos mucho más sociales, según el Índice de Desarrollo Humano (IDH) del Programa de Naciones para el Desarrollo (PNUD), Cuba se situaría en el número 59 de una lista de 187 países, encajado en los estados de Desarrollo Humano Alto. Dentro de la región de América Latina y el Caribe, se posiciona por encima de la media, alcanzando el 0,780. Con las consabidas mejoras en educación y salud que introdujo la revolución cubana, hallamos una población con tasas de alfabetización que rondarían el 100\%. Unos bajísimos índices de abandono escolar, que no superan los cuatro puntos porcentuales, con un periodo de formación educativa básica sobre los diez años. En la misma línea, se calcula que el gobierno cubano destina más del $12 \%$ de su PIB a la educación y formación de la población nacional. Otro punto significativo de las políticas sociales del gobierno comunista, ha sido su reputado sistema sanitario. Una sanidad universal y pública que supone en torno al $9 \%$ del gasto público, dentro de una esperanza de vida al nacer estimado por el último en 79,3 años para ambos sexos. La calidad de los servicios sanitarios cubanos están notablemente valorados por los organismos internacionales.

No obstante, las notas más negativas de la República de Cuba vienen dados por los derechos políticos y sociales. Human Rights Watch califico en 2012 al estado caribeño, como el único país de América Latina donde se reprimen casi todas las formas de disenso político. La organización no gubernamental se hace eco de las denuncias del Consejo de Relatores de Derechos Humanos de Cuba (CRDHC), donde se extrae que existen reconocidos oficialmente 43 ciudadanos encarcelados por razones políticas. Otros muchos cubanos que critican pública y sonoramente al régimen son sometidos a procesos judiciales que no cumplen las garantías mínimas. Las penas por desacato y alteración del orden público pueden llegar a los cincos años de cárcel. (Human Rights Watch, 2012:1-2). Asimismo, el aparato del régimen no duda en recurrir a un entramado de leyes y figuras normativas, como la 
Hernández, David. Reformulando la revolución cubana. La presidencia de Raúl Castro (20082013)

insubordinación o desobediencia civil, que maniatan las posibilidades de disensión entre la sociedad civil (Rico, 2009). Según, la Comisión Cubana de Derechos Humanos y Reconciliación Nacional, en 2011 se dieron más de 2000 detenciones de carácter represivo. Aunque, se imaginan que el número de presos y detenidos por razones políticas son muchos más debido a que las autoridades cubanas no facilitan información.

Por otra parte, no hay que olvidar que el gobierno castrista mantiene el monopolio absoluto sobre los medios de comunicación, donde la posibilidad de llegar a las informaciones extranjeras está sumamente restringida. Aún más, el gobierno cubano se encarga estrictamente de controlar la entrada y salida de medios de comunicación extranjeros, también supervisa concienzudamente su trabajo dentro de la isla. Es comúnmente sabido que el acceso a Internet está limitado por mecanismos gubernamentales, sirviendo de severos filtros que impiden una comunicación fluida con el exterior (Sánchez, 2010). De esta forma, se evita de un modo más o menos efectivo que las críticas externas, protagonizadas principalmente por disidentes en el exilio, puedan llegar a la isla.

Aunque este nivel coactivo se ha mantenido inmutable en la presidencia de Raúl Castro, las muestras de oposición parecen crecer, gracias en parte a las nuevas tecnologías, dándole a las acciones y movimientos disidentes una mayor repercusión mediática tanto fuera como dentro del país. No obstante, el gobierno comunista no parece dar muestras de flaqueza (Vicent, 2010) y debido al inmutable férreo control del régimen, la oposición que intenta movilizarse en la propia Cuba se encuentra frágilmente organizada, aunque destacan grupos cuyas acciones tienen enorme trascendencia social, como las Damas de Blanco. Con todo ello, no es errado afirmar que la auténtica fuerza discrepante viene desde fuera, donde han conseguido en los últimos tiempos importantes apoyos internacionales.

\section{EL APOYO DE DOS ALIADOS: CHINA Y VENEZUELA}

\subsection{El compañero comunista asiático}

Primeramente, antes de exponer concisamente las relaciones exteriores del país comunista latinoamericano con la segunda potencia mundial, China, y una de las históricas potencias regionales, Venezuela; debemos justificar que el capítulo a punto de empezar daría para elaborar sendos trabajos, pues es indudable las dimensiones y amplitudes de la interrelación entre la isla y dichos aliados. Segundo, nos centramos en estos dos países, porque como veremos a continuación, se han consolidado como los aliados más fiables que posee La Habana en el contexto internacional. Este grado de amistad viene determinado en gran medida por el apoyo financiero, logístico y de recursos concedidos por los dos aliados al régimen, que han supuesto una garantía de estabilidad en momentos de debilidad.

Centrados en los vínculos con la República Popular de China, podemos señalar que Pekín, como lo fue en su día Moscú, ha sido uno de los tradicionales aliados políticos del régimen de Fidel Castro. Cuba fue el primer país latinoamericano en reconocer el gobierno comunista continental en 1960 (Díaz Vázquez, 2010: 1-2), y con la visita oficial del Che Guevara se propició la firma del primer acuerdo de colaboración en materia económica y tecnológica. Desde entonces, la cooperación 
Hernández, David. Reformulando la revolución cubana. La presidencia de Raúl Castro (20082013)

entre ambas naciones ha sido constante a lo largo del tiempo, e indiferente al devenir de las circunstancias mundiales. Así, a pesar del distanciamiento de Pekín sobre el Kremlin tras la política de destalinización de Jrushchov; después de la desaparición de Mao y la apertura del país asiático a Occidente, con su consabida capitalización. Incluso, tras el decaimiento de la Unión Soviética, China ha seguido manteniendo una correspondencia estrecha con el gobierno cubano. De hecho, los dos primeros decenios del siglo XXI han sido testigos del ascenso global de la república oriental, al mismo tiempo que se han consolidado las relaciones mutuas, pasando a convertirse la potencia china en el segundo socio comercial y económico de la isla, por detrás sólo de Venezuela y adelantando al conjunto de inversiones de la Unión Europea (Vicent, 2011). De igual manera, en los últimos lustros la alianza sino-cubana ha pasado a adquirir para los dirigentes caribeños un cariz prioritario y estratégico. Se ha pasado del tradicional alineamiento ideológico, a reforzar los ligámenes económicos esenciales para la pervivencia del régimen. Esto es así, gracias principalmente al exponencial aumento de las inversiones chinas en América Latina, inducido fundamentalmente por su vertiginoso crecimiento y la urgencia de materias primas.

Empero, es innegable que en una sociedad internacional cada vez más fragmentada, donde China aspira a consolidar y expandir su liderazgo regional y mundial, el politburó comunista chino, ha encontrado en el país situado a las puertas del hegemón norteamericano un punto de refuerzo para menguar las influencias de la Casa Blanca, en una región de creciente trascendencia para su devenir. (Serbín, 2012). A su vez, reiteradamente lo explicamos, Cuba ha encontrado en la cordialidad de Pekín una válvula de escapa a las presiones estadounidenses, un modo de moderar los efectos de más de cuarenta años de embargo y aislamiento.

Igualmente, centrados en la materia meramente comercial, es idóneo mencionar que desde 1988, las relaciones económicas y financieras entre ambas naciones han sido articuladas por la Comisión Mixta Intergubernamental para las Relaciones Económicas y Comerciales (CMIREC), donde se proyectan y discuten los diferentes convenios y acuerdos, superando los mecanismos habituales de concertación, llegando a programar consorcios anuales y quinquenales. No obstante, desde finales del siglo XX la praxis sustancial de los intercambios se vio alterada, imponiéndose unas bases crediticias y formas de pago acordadas por las partes contratantes (Díaz Vázquez, 2008). Concretamente, las fuentes oficiales, estiman que el intercambio comercial entre ambos países ha llegado a sobrepasar los 1.800 millones de dólares en los últimos años, creciendo un 15\% a lo largo del siglo XX (Díaz Vázquez, 2010: 2). Aunque, como ocurre en cualquier ilación entre un agente más desarrollado que otro, el balance es favorable para los saldos chinos, ya que la parte asiática representa para la isla su segunda fuente proveedora.

En un breve repaso observamos que la cuestión petrolífera ocupa un lugar preferencial. La presencia de las compañías orientales en la isla, adquieren una significación semejante a Venezuela, donde la tecnología incorporada por las inversiones chinas ha permitido aumentar las capacidades de extracción. Obviamente, la reciprocidad entre el régimen isleño y el gigante comunista no se ha limitado al campo de los recursos energéticos. China se ha convertido en un apoyo financiero fundamental para los hermanos Castro, concediendo facilidades de liquidación de la deuda acumulada. Otros convenios han concedido fondos de 
Hernández, David. Reformulando la revolución cubana. La presidencia de Raúl Castro (20082013)

subvención valorados en unos 200 millones de dólares, para el equipamiento tecnológico del país latinoamericano (Díaz Vázquez, 2010: 2-3). Por otra parte, China ha abierto las puertas a las exportaciones cubanas de níquel, azúcar, tabaco, ron, mariscos y productos de biotecnología (Díaz Vázquez, 2008). Concluyentemente, aunque las relaciones interestatales se han visto sobrepasadas el componente elementalmente economista por las razones económicas; entre La Habana y Pekín continúan apreciándose unos intereses y objetivos que ahondan en una idiosincrasia semejante.

\section{REVOLUCIÓN DESDE LA HABANA HASTA CARACAS}

La llegada al poder de Hugo Chávez ha marcado un antes y un después en la evolución reciente de la política Latinoamérica. La figura del líder bolivariano ha supuesto uno de los referentes más importantes de los últimos años para Cuba, convirtiéndose en el principal aliado y bienhechor del régimen comunista. $\mathrm{El}$ chavismo y la revolución cubana se han entremezclado en una simbiosis algo desigual, que ha propiciado junto a otros estados periféricos de la zona, un nuevo polo de subversión y contestación. Por ello, al hablar de las relaciones CubaVenezuela, estamos aludiendo directamente al comportamiento exterior tomado por el ejecutivo bolivariano. De igual modo, nadie duda, inclusive dentro del aparato cubano, que la benevolente política venezolana hacia el país caribeño, ha permitido preservar el statu quo interno pese a las vicisitudes del contexto mundial y ciertos movimientos contestatarios al sistema castrista.

Las relaciones de Hugo Chávez con los hermanos Castro se remontan a la década de los noventa, cuando el joven militar tras la errada intentona golpista de 1992 y su posterior arresto de dos años, es invitado por el propio Fidel Castro a La Habana en diciembre de 1994, donde se cimentó una amistad personal clave. Posteriormente, como no podía ser de otro modo, los encuentros entre ambos gobiernos han transcendido más allá de las simples afinidades ideológicas. La Venezuela Chavista ha contemplado en la isla caribeña, no sólo una inspiración política y un aliado infalible, sino también una pieza clave en la construcción de su tan ansiado eje bolivariano regional (Garrido, 2009: 131-132).

Antes de la llegada del Movimiento Quinta República (MQR) las relaciones entre Venezuela y el régimen cubano no excedían de una cordialidad diplomática y algún intranscendente acuerdo comercial. Desde 1999, la cuba castrista se convirtió en una de las prioridades de la política exterior del Palacio de Miraflores, comenzando con acuerdos de petróleo caracterizadas en el tiempo por unas condiciones de pago muy favorables, que año a año fueron ampliándose a diversos aspectos políticos e institucionales. El objetivo final es reducir la posible influencia de los intereses norteamericanos en la Cuenca del Caribe, al mismo tiempo que Venezuela intenta extender los suyos a través de Petrocaribe. De la misma forma, Hugo Chávez ha encontrado en la revolución cubana y la figura de Fidel Castro, la imagen legitima entre sus admiradores, para impulsar medidas socialistas en su país (Amor, 2010: 212-213). Es decir, su interés hacia el aliado caribeño va más allá de lo puramente comercial, ya que para muchos latinoamericanos Cuba sigue siendo ese gerifalte rebelde al imperialismo norteño. 
Hernández, David. Reformulando la revolución cubana. La presidencia de Raúl Castro (20082013)

Desde la perspectiva venezolana, Cuba se integra en los proyectos regionales impulsados desde Caracas, como son la Alianza Bolivariana para los Pueblos de Nuestra América (ALBA) y el mencionado Petrocaribe. La organización bolivariana emergió destacadamente dentro de un regionalismno post-liberal que sacudió el nuevo siglo en Latinoamérica, con unas bases fundacionales de arraigados componentes ideológicos (Serbin, 2012: 155-156). La concertación ha sobrepasado los límites puramente comerciales, para alcanzar unas pretensiones políticas, una integración regional marcada por la completa determinación ideológica. Petrocaribe es el punto de partida de un acuerdo de colaboración entre catorce países del área caribeña, alentados por la retórica emancipadora socialista del régimen cubano y las facilidades de acceso a barriles de petróleo ofrecidas por la compañía estatal PDVSA (Petróleos de Venezuela, Sociedad Anónima), que buscaban en las reservas venezolanas unos precios menos abusivos.

Asimismo, la política exterior cubana siempre ha sido diseñada con la prioridad absoluta del mantenimiento del régimen político establecido tras 1959, sea cual fuera el contexto internacional. Dicha exigencia se escenifico con mayor resolución tras el derrumbamiento de su gran protector soviético, que le llevaron a mediados de los noventa a apostar por la carrera política del comandante venezolano, conocedores del potencial geopolítico que posee la patria de Bolívar. Al contrario de lo que la realidad inicial nos podría llevar a deducir, Cuba siempre ha elaborado una política exterior propia, incluido durante la Guerra Fría (Domínguez, 2009a: 14-15). Puede haberse escondido tras los potenciales de socios más capacitados, pero sus intereses siempre han predominado en sus conductas externas. Por ello, sería verdaderamente ingenuo creer que los hermanos Castro se han convertido en unos subordinados de las inclinaciones chavistas. Siendo los asuntos externos una cuestión de supervivencia, el régimen nunca cederá sobe su timón.

Igualmente, las relaciones con Caracas son formidablemente beneficiosas para los isleños, encontrando salidas ocupacionales en la administración general venezolana. Principalmente el personal sanitario, gracias a los programas sociales del Barrio Adentro y Centro de Diagnóstico Integral. Empero, también la cooperación cubana ha llegado a formar parte de la seguridad personal del propio mandatario venezolano, del personal de aduanas, puerto y aeropuertos; y ayudar en la implantación de programas agrícolas entre otros (Vinogradoff, 2013). Con todo ello se ha conseguido reequilibrar las balanzas de la maltrecha economía cubana, exportando el talento de sus profesionales en campos ampliamente desarrollados. Por otro parte, es públicamente conocido los reportes positivos en recursos energéticos, con más de 35 mil barriles diarios que llegan a la isla, con precios asumibles por la economía autóctona. Además, las relaciones con Venezuela han proporcionado a Cuba el acercamiento a otras naciones de la región. Del mismo modo, las presiones chavistas han ido definiendo un medio regional más propenso al gobierno de los hermano Castro.

\section{LA REVISIÓN DE LOS PRINCIPIOS COMUNISTA}

\subsection{Reformas económicas}

Los principales esfuerzos transformadores del gobierno de Raúl Castro están fundamentalmente focalizados a reestructurar y modernizar, dentro de las premisas 
Hernández, David. Reformulando la revolución cubana. La presidencia de Raúl Castro (20082013)

básicas del ideario estatal, la economía cubana. Las prioridades de sus políticas han sido atajar los problemas económicos más acuciantes, que lastraban el crecimiento coetáneo de la isla. El propósito final obviamente sería la pervivencia del socialismo cubano en el siglo XXI, provocando que se atiendan preferencialmente los problemas artificiales que los verdaderamente estructurales. De esta forma, desde hace un lustro, se ha impuesto en todo el país un clima de voluntad de reformas y cambio, programado por las mismas autoridades, que buscan una nueva vía de legitimación. Así, el liderazgo de Raúl Castro que carece del carisma de su hermano, ha obligado a potenciar el pragmatismo en detrimento del idealismo. Los cuadros de poder son conscientes de la frágil situación en la que se encuentra la nación, lo que ha hecho inevitable encarar, antes o después, una secuencia de firmes reformas (Alonso, 2012: 11-13). Es decir, se reconoce oficialmente la necesidad de reformar el sistema, pero sin afirmar que la revolución pudo caer en equivocaciones.

A pesar de ello, dentro de esta vorágine de medidas encaminadas a favorecer la actualización de la economía, el PIB de Cuba creció según datos de la CEPAL un 2,7\%; los principales motivos de este ascenso, como señala la Comisión Económica, fueron el continuo aumento del consumo privado y la mejora de la cuenta corriente, que facilitó el avance en la regularización de pagos a acreedores extranjeros. En los primeros meses de 2012 se alcanzó un crecimiento del 3\% como resultado principalmente del dinamismo que comenzaba a adquirir la economía interna, básicamente alentada, de nuevo, por el consumo privado y una inversión pública que empieza a centrarse en los sectores claves, (CEPAL, 2012).

Una de las intenciones presidenciales más sugerentes, han sido diversificar la actividad productiva y reducir el peso de los negocios del Estado. Empero, dentro de la estructura del PIB, más del $76 \%$ de su composición está formada por las actividades estatales, sobre todo las relacionadas con el sector servicios, que han llevado recientemente a una dependencia en la balanza comercial de los beneficios extraídos por las exportaciones de elementos de dicho sector. En contraposición, dentro de la configuración productiva se manifiesta el bajo peso relativo de los sectores de la agricultura, industria, construcción y transporte (Everleny, 2010a). Así, desde una perspectiva general de la economía cubana, podremos comprobar que sus esencias más deficitarias siguen muy presentes, y no se espera que las reformas anunciadas vayan a solucionar todas estas vicisitudes próximamente.

Concretamente, orientados en la descripción de las políticas económicas, cronológicamente podemos situar la andadura reformista desde 2008, aunque el debate entre los órganos centrales estaba ya presente desde 2007. A lo largo de ese tiempo se crearon infinidad de grupos de trabajo, con la intención de presentar al Congreso del Partido un paquete de medidas que atendieran a los requerimientos. Con ello, el programa oficial de objetivos llego en el VI Congreso del Partido Comunista en abril de 2011, donde se debatió y finalmente se aprobó la publicación de los Lineamientos de la Política Económica y Social, marcándose las directrices a seguir en los próximos años. En lo relativo a las medidas económicas, destacan los esfuerzos por aumentar los rendimientos del siempre malogrado campo cubano, entre otras cosas, ampliando el acceso de los agricultores al usufructo del suelo. También, se ha buscado avanzar controladamente en la liberalización del mercado y la incorporación de la iniciativa privada, siendo la principal vía de escape la figura del cuentapropista. Igualmente reseñable ha sido la tendencia a reducir el peso de la 
Hernández, David. Reformulando la revolución cubana. La presidencia de Raúl Castro (20082013)

administración pública, imponiendo una severa disciplina presupuestaria y disminuyendo tanto su plantilla como algunas de sus funciones. (Alonso, 2012:1314). En los ámbitos fiscales y monetarios se han aplicado unas políticas de naturaleza restrictiva, todavía se persigue alcanzar un modelo monetario más eficaz, orientado hacia la convertibilidad de una moneda única; además, intentado equilibrar el déficit público.

Sobre estos últimos objetivos mencionados, se atajó uno de los asuntos que más ha calado entre la población, hablamos de la supresión de la libreta de racionamiento. Para la sociedad cubana ha sido todo un símbolo del proteccionismo social, generando que su eliminación ha sido una de las decisiones más controvertidas realizadas por el gobierno de Raúl Castro (Alonso, 2012: 30-31). Mediante esta libreta el Estado cubano asignaba mensualmente una cesta de alimentos y productos básicos a las familias, a precios muy por debajo de los mismos costes de producción. Lo que se está haciendo año a año, es ir eliminando determinados elementos de la cesta, que pasan a tiendas estatales a precios muy similares a los de un mercado libre. Su desaparición es una tentativa más de acabar con el sistema de subsidios generalizados. Por otra parte, se ha intentado combatir la fuerte presencia del sector informal, donde los cubanos intentaban compensar sus escasos ingresos legales con actividades no reconocidas oficialmente, (Alzuguray, 2012: 4142). Para ello, se iniciaron diferentes aumentos salariales, estrechamente vinculados a los grados profesionales, permitiendo que el consumo privado, el cual se estaba convirtiendo en el principal motor del crecimiento, no se viera desacelerado. Todo parece indicar que encaramos una nueva etapa, donde la iniciativa privada irá reemplazando a la pública en muchos ámbitos.

Desde una perspectiva general, podemos señalar que el período de transformaciones iniciado, intenta profundizar en la descentralización de la economía, cediendo cada vez más protagonismo a los actores económicos particulares (Cordoví, 2012: 83). No obstante, la presencia del Estado sigue siendo elemental en el devenir de Cuba, sin duda alguna, hay sectores intocables para las autoridades. Sorprendentemente, una de las políticas económicas que más pronto se vio afectada por las reformas, fueron las medidas públicas destinadas a fomentar el empleo y dar cobertura a los desempleados. Uno de los tradicionales objetivos del gobierno comunista, ha sido alcanzar el pleno empleo, o mejor dicho, que ningún cubano se quedará sin trabajar. Esta premisa contrasta con los últimos postulados del gobierno de Raúl Castro, donde se ha reconocido en varias ocasiones la necesidad de disminuir el personal de la administración pública, anunciándose una reducción de plantilla de más de medio millón de empleados (Mesa-Lago, 2010). Además, se reconocía que en ciertos sectores, principalmente del gremio industrial, en ocasiones padecía de un exceso de mano de obra, que generaba la ineficiencia de la producción. No hay que olvidar que el estado ha tenido un papel altamente intervencionista en el mercado laboral, conducía a una designación de recursos, enormemente ineficiente, que producía subempleo y la búsqueda de ingresos más allá de los estipulados.

Por tanto, existe la clara intención de reducir la capacidad de designación de la administración general, reconociendo problemas por mantener a la casi totalidad de la población activa empleada (Padura Fuentes, 2012), se intenta que los espacios abiertos a los pequeños negocios y sectores privados como el turismo, permitan 
Hernández, David. Reformulando la revolución cubana. La presidencia de Raúl Castro (20082013)

asimilar toda aquella mano de obra que el Estado es incapaz de retribuir. Aún más, cuando el gobierno ha comenzado a moderar los subsidios de desempleo, concentrándolos en las familias más desfavorecidas, intencionadamente para menguar el gasto público y favorecer la búsqueda individual de trabajo.

En lo relativo a la política fiscal, como hemos mencionado, nos situamos en pleno proceso de racionalización de gastos y del control de los recursos. Las disposiciones públicas pasan por ser auditadas por un nuevo órgano, subordinado directamente al Consejo del Estado, la Contraloría General de la República, quien se encarga de asignar los recursos y evaluar los destinos de los mismos. A través de la misma línea restringente, en 2011 comenzó la paulatina supresión de unidades presupuestarias estatales, con el objetivo de que las únicas destinatarias fueran las ligadas a conservar la calidad del sistema educativo y sanitario y el sostenimiento de la seguridad social. Empero, uno de los baluartes de la revolución socialista, que siempre ha pregonado la igualdad de clases, comienza a fracturarse debido a que el auge de nuevos sectores, unidos a la patente existencia de una economía sumergida, y la fuerte presencia de las remesas, ha ido atomizando la sociedad cubana e incoando diferencias notables (Padura Fuentes, 2012: 33-34).

Con todo ello, en lo referido a la fiscalidad, se ha querido disminuir notablemente los gastos no prioritarios. Mediante estas actuaciones el gobierno cubano preveía para el 2012 un déficit fiscal del 3,8\% del PIB, (CEPAL, 2012). A tenor de lo dicho, se ha buscado equilibrar las cuentas públicas, no sólo por la vía de los gastos, sino también atrayendo más ingresos, que ha supuesto un aumento de algunos niveles impositivos. Sobre los impuestos, donde ha existido la tradicional política de no cargar sobre los ya bajos salarios de la población, existe la intención de compaginar el crecimiento de los niveles de renta, con una mayor disposición impositiva, para ello se ha comenzado a confeccionar una nueva ley tributaria.

Por otra parte, los ámbitos crediticios y monetarios no han escapado últimamente a los programas de lineamientos y actualización nacionales. En diciembre de 2011 entró en vigor una de las políticas más rupturistas e innovadoras, según la cual, y sin injerencias estatales, los bancos locales podían otorgar crédito a cualquier ciudadano aparentemente sin restricciones. La premisa recogida era dar facilidades principalmente a los campesinos y cuentapropistas, facilitando la inversión particular en aquellos sectores donde el Estado no llegaba hacerlo.

Durante los últimos años se ha logrado renegociar buena parte de la deuda externa, a tasas de interés más bajas y plazos más largos. (CEPAL, 2012). Es idóneo indicar, que durante la década de los noventa, bajo la tremenda oscilación que sufrió la economía cubana, se impuso una actitud desinteresada hacia las obligaciones con el exterior. Sin embargo, estas pautas se han modificado desde 2008, intentado dar mayor credibilidad al sistema financiero interno. Existe el férreo compromiso para los próximos años de responder a los compromisos prestamistas externos, buscando así volver a atraer cuantiosas inversiones foráneas.

En cuanto a la política cambiaria, se siguen manifestando problemas estructurales que han arrastrado el óptimo funcionamiento económico durante casi toda la revolución, siendo el principal problema ha sido la doble moneda. Debemos tener presente que en Cuba no existe un mercado de intercambio abierto, sino que se 
Hernández, David. Reformulando la revolución cubana. La presidencia de Raúl Castro (20082013)

encuentra señalado por las directrices marcadas por el Comité de Política Monetaria del Banco Central, que ante todo persigue el equilibrio del mercado de cambio y la estabilidad de los precios (Pavel Vidal, 2008: 88-89). Todo ello ha conjugado una situación falsa entre los ascensos reales de los precios y los valores nominales calculados por las autoridades. De la misma manera, dentro de un mercado de flotación sucia, con un sistema cambiario bajo el control estatal, el Banco Central se erige más que nunca en la institución más significativa del ámbito monetario cubano. Incluso, desde los noventa destaca la figura de las Casas de Cambio S. A, que han constituido una portentosa red nacional de cambio donde los cubanos pueden acceder a la compra y venta de monedas. A pesar de esto, hasta el momento no se ha definido formalmente un itinerario para aproximarse a la unificación, aunque se están realizando algunos ensayos en un grupo de empresas que funcionan con diferentes tipos de cambio. Los debates y estudios gubernamentales instituidos muestran el claro empeño por lograr, de una vez por todas, acabar con la dualidad monetaria. Una dualidad, que entre otros muchos males, desemboca en desequilibrios acentuados entre el valor de los salarios percibidos y los precios de los productos, lo que incide en aumentar la desigualdad social (Everleny, 2011: 1920). Así, elementalmente se pretende la restauración del peso cubano como único signo monetario del país, y finalizar con la fusión que mantiene con el peso convertible. La convertibilidad monetaria va a representar en los próximos años, un tema clave en la política económica cubana.

Al principio de este punto anunciamos que entre las más importantes reformas económicas aplicadas por el gobierno cubano, se encontraban las relativas a la mejora de la productividad agrícola y la gradual liberalización del trabajo por cuenta propia. Del mercado laboral, dentro del sector privado, despunta la figura del cuentapropista, calculándose oficialmente en el 2012 más de 380.000 cubanos que tienen su propio negocio. La liberalización de las condiciones de la normalización de los cuentapropistas, eran una de aquellas medidas anunciadas por Raúl Castro en 2008 de necesaria inmediatez, donde las prohibiciones y trabas administrativas que perturbaban su normal funcionamiento debían ser eliminadas (Dilla Alfonso, 2012). La razón principal es que el mercado del cuentapropista había sido uno de los acicates de la economía sumergida, que ahora las autoridades intentaban rescatar.

Según han pasado los años, las actividades de los cuentapropistas han encontrado cada vez más respaldo estatal, se ha ido ampliado la gama de operaciones en las que pueden entrar los negocios privados, tanto desde la vía de la oferta como de la propia demanda. (Alonso, 2012: 12-13). Reiteradamente advertimos, que se quiere reemplazar al Estado en todas aquellas relaciones comerciales donde resulte más dinámico la intervención del interés privado, constituido en un pequeño negocio, reservando plazas más grandes aún para lo público. Finalmente, el propio Raúl Castro reconocía en el VI Congreso del Partido, que toda aquella mano de obra que las administraciones y empresas públicas no podían contratar, tendrían que ser asimiladas por las actividades privadas. En los últimos tres años, ha habido enormes avances en la liberalización de dicho mercado, recogiéndose las principales medidas económicas de desestatalización. Entre otras disposiciones, se han aprobado casi 200 actividades por cuenta propia, se autorizó emplear a trabajadores no familiares en las ocupaciones autorizadas, donde se posibilita la venta de bienes y servicios a entidades estatales; se otorgaron más facilidades para arrendar locales y la regulación de pequeños préstamos a los cuentapropistas para la compra de bienes, 
Hernández, David. Reformulando la revolución cubana. La presidencia de Raúl Castro (20082013)

insumos y equipo. Además, se ha establecido un régimen especial de pensiones de seguridad social para dichos trabajadores, de afiliación obligatoria (Mesa-Lago, 2011:2).

Pese a todo lo explicado, la verdadera alma mater de la política económica de los gobiernos de Raúl Castro es el sector de la agricultura. Históricamente, el campo y su explotación han escenificado un balasto insoslayable para los cálculos comunistas, que nunca han conseguido resolver. La ineficacia de todas las distintas medidas implementadas, han estancado la producción agrícola, arrastrando consigo los perjuicios de una alta dependencia del exterior en materia de importaciones. Las estimaciones oficiales indican que se importa cerca del $80 \%$ de los alimentos que consume la población cubana, a un coste anual cifrado en torno a los 1.000 millones de euros, mientras que casi un 30\% de un total de 6,6 millones de hectáreas de tierras estatales están ociosas (Mesa-Lago, 2011: 2-4). Para corregir estas calamitosas deficiencias, que permitieran aumentar la producción y reducir las importaciones, se aprobó en 2008, entre las primeras medidas del nuevo presidente, una nueva ley de usufructo, que ampliaba las condiciones de acceso de los agricultores, individuos o cooperativas a la explotación del suelo.

Empero, como demuestra la industria azucarera, tradicionalmente la más importante de la actividad primaria, la producción de caña de azúcar ha ido disminuyendo en sus cifras desde hace más de dos décadas, sin que las reformas consiguientes hayan resuelto sus problemas enquistados (Everleny, 2010a). Además, aunado a todas las dificultades de los sectores de recursos y manufactureros históricos, se le une la reducción de gastos en dichas empresas dependientes la mayor parte de los recursos financieros del ministerio, que ha tenido negativas repercusiones en los rendimientos generales. No obstante, la normativa puede resultar escasa en sus resultados, pero conlleva un avance considerable en la superación de las prohibiciones a la propiedad privada en el campo. Más, aún siguen existiendo fuertes cortapisas, las extensiones de las parcelas cedidas no pueden sobrepasar las 13,4 hectáreas, la propiedad de la tierra sigue siendo del Estado, y éste concede contratos de cesión para un plazo de diez años. Además, el Gobierno obliga al usufructuario vender al Estado una cuota de la cosecha, hasta el 70\%, a un precio verdaderamente inferior al de mercado, reclamándole que en menos de dos años la tierra, mucha de ella casi completamente virgen, produzca cuantiosamente (MesaLago, 2011: 4-5). En cambio, las obligaciones de los que desean adquirir su propia parcela exigen amplias responsabilidades más, debiendo pagar tres impuestos referidos a la posesión y el uso de la tierra, sobre la fuerza de trabajo, los propios de la seguridad social y sobre los ingresos personales. Con todo ello, pudiera parecer que el gobierno ha querido ganarse el beneplácito de la población en lo formal sobre un asunto reclamado desde hace años, mientras en su contenido sigue dando señales de premisas muy restringentes. Aún sigue mostrando un carácter escasamente atractivo para cualquier trabajador del mundo rural que quiera labrar sus propios terrenos. Resultantemente, no debería extrañar que los datos extraídos tras la aplicación de esta controvertida medida no sean nada gratificantes. Según las estadísticas hechas públicas durante el 2011 y 2012, se habían entregado más de un millón de hectáreas a más de 120.000 campesinos. Sin embargo, los datos siguen siendo negativos, con unas tierras explotadas que no pasan del $50 \%$. (Alonso, 2012:33). No han pasado cinco años de su implementación y ya se piensa 
Hernández, David. Reformulando la revolución cubana. La presidencia de Raúl Castro (20082013)

en una reformulación de la medida, a pesar de que se quiere mantener la preeminencia de la fuerza pública.

En otras categorías, tal vez macroeconómicamente menos relevantes que adquieren su repercusión en la cotidianidad de la vida cubana, se subraya la disminución de impedimentos burocráticos al mercado interno de consumo, ampliando notablemente los productos al alcance de los cubanos. Aunque no es menos cierto, que muchos de los elementos a comercializar debido a sus altos precios, se encuentra lejos de poder ser adquiridos por el sueldo medio de un ciudadano isleño. Se ha permitido desde el año 2008 la venta de líneas y móviles, la comercialización de ordenadores, pese a que el acceso a Internet se encuentra limitado; también se ha permitido la compra de otros productos domésticos como televisores, DVD, o cualquier tipo de utensilio para el hogar, así como el hospedaje de turistas nacionales en los hoteles (Alonso, 2012: 30-31). Además, se eliminaron por completo las restricciones a la compra y venta de automóviles. Mediante estas prerrogativas el gobierno intenta estimular el consumo de aquella clase media que empieza a emerger, principalmente en los núcleos urbanos, siendo esenciales para el crecimiento.

\section{REFORMAS SOCIALES Y POLÍTICAS}

Analizando exhaustivamente la presidencia de Raúl Castro desde 2008, comprobamos el carácter eminentemente económico de gran parte de sus medidas. Es cierto, que las más significativas reformas introducidas en la isla, son expuestas con la finalidad de mejorar la debilitada economía caribeña. Ahora bien, las políticas introducidas pueden tener unas consecuencias sociales, en muchos casos imprevistas. Asimismo, todo el proceso transformador abierto con la llegada al poder del general de las Fuerzas Armadas, ha generado un importante debate ideológico interno, cuyas disensiones han transcendido y han evidenciado un sistema no tan unido. Por lo tanto, la presidencia de Raúl está marcada por los cambios en el modelo económico, mientras que las acciones sociales y políticas han tenido un papel relegado. En este sentido, no se han percibido aún señales algunas de alteración en el statu quo político establecido, así las directivas sociales han tenido un peso bien escaso, no representando una prioridad.

No obstante, muchas de las prerrogativas implementadas tendrán, obviamente, sus efectos sociales. Las políticas restrictivas del gasto público, que han afectado severamente a muchos de los subsidios, repercuten directamente sobre el riesgo de favorecer las desigualdades sociales. El ámbito donde Cuba ha sido un referente internacional, en la actualidad se verá mermado, dejando un panorama más incierto a la población, (Pavel Vidal, 2011). Esto es, las reformas llevadas a cabo tendrán variados costes sociales, incalculables por el momento, a los que el gobierno se verá desafiado a gestionar dentro de escaso tiempo. Hablamos no sólo de las reducciones en las prestaciones estatales, sino también el incremento de la inseguridad en el empleo derivadas de las eliminaciones de empresas públicas, que puede desembocar en la podredumbre de numerosos cubanos (Alonso, 2012: 15). A este respecto, el estado socialista corre también el peligro de ver degradado sus universales y valiosos sistemas de educación y sanidad. Además, entre otros factores, la entrada de remesas, los dólares llegados por el turismo internacional y la constitución de negocios privados inducen a crear nuevas diferencias. 
Hernández, David. Reformulando la revolución cubana. La presidencia de Raúl Castro (20082013)

Si se tiene en cuenta que el Banco Mundial considera que los ingresos por debajo de 70 dólares mensuales son indicadores de pobreza, y el promedio de los cubanos no alcanza esa cifra, nos encontramos ante un horizonte complicado para muchos ciudadanos (Blanco, 2012: 63-64). Sin duda alguna, las autoridades comunistas se verán premiadas a tomar políticas sociales para resolver ciertas tensiones que surgirán dentro de un sistema que modifica sus costumbres sin alterar los pilares básicos. La cuestión predominante, es que existen tras la figura de los Castro, unos cuantos bloques de poder, que dificultan la rápida toma de decisiones por las divisiones internas.

Dentro de un sistema extremadamente opaco, podemos distinguir varios sectores de influencia, que se disputan los puestos de decisión para hacer prevalecer sus intereses a la hora de formular los programas. El recién nombrado presidente del Consejo de Estado se atrevió a renovar algunos cargos del gobierno y partes del aparato territorial del partido, pero procurando mantener los equilibrios de poder en los que se sustentan la estabilidad del sistema (Bayo, 2011). Sobresalen las Fuerzas Armadas Revolucionarias, dando cabida a las tradicionales e históricas cúpulas comunistas, que comienzan a asumir más responsabilidad en contraposición a las figuras del partido y donde durante décadas impuso su autoridad Raúl Castro. Concluyentemente, se están imponiendo unas posturas más tecnocráticas que ideológicas, supeditando formulas eficientes y factibles más que puramente políticas.

Por otro lado, quedan los cuadros del Partido Comunista Cubano, residencia de los paradigmas más clásicos de la revolución, que han supuesto siempre el ala más conservadora y retroactiva del sistema. No obstante, dentro destacan los niveles más jóvenes, que muestran una tendencia más aperturista (Dilla Alfonso, 2008: 4243), pese a que existe una enorme resistencia por producir cambios generacionales. La fuerza política es copada por los octogenarios más reticentes a transformaciones, temerosos a que se cuestione ásperamente los pilares comunistas.

Por el momento, Raúl Castro sólo se ha atrevido a cambiar los equilibrios con ciertas propuestas que aún se encuentran en estudio, seguramente generando agudos debates entre los diversos niveles de autoridad. Desde las más altas esferas se ha hablado ya de la necesidad de limitar los mandatos de los dirigentes, de renovar los estatutos del mismo Partido Comunista y la creación de comisiones para actualizar las estructuras del partido y del gobierno (Bayo, 2011: 2-3). Con todo ello, desde 2008 el gobierno ha ido prometiendo, a lo largo de infinidad de discursos, una remodelación del sistema político, que le permita ser más permeable y favoreciera la participación de los ciudadanos en los procesos decisorios. Se quiere reforzar los órganos municipales, asegurando que existirá una descentralización de los polos de poder hacia las instituciones provinciales y locales. Se prevé, aún sin determinar, más capacitación a las Asambleas ciudadanas (Alzugaray, 2009), donde se quiere promocionar la participación ciudadana.

En la misma línea, se ha intentado dar voz a las distintas agrupaciones y asociaciones, con la finalidad de acercar al sistema por otras vías que no sean las ofertadas por el inflexible control del partido comunista. En los últimos tiempos, se ha podido escuchar a representantes sindicales y cooperativistas en foros anteriormente exclusivos para miembros de partido y militares. No obstante, la revolución desde sus inicios se encargó de potenciar la asociación de trabajadores 
Hernández, David. Reformulando la revolución cubana. La presidencia de Raúl Castro (20082013)

en cooperativas y sindicatos, que han transcendido del ambiente laboral, para convertirse en entidades sociales, que vertebran la sociedad cubana (Alzugaray, 2009: 40-41). Reseñable, por ejemplo, es la participación de la Asociación Nacional de Agricultores Pequeños (ANAP) y la Central de Trabajadores de Cuba (CTC), entre otros, en la deliberación de un sinfín de nuevas leyes, posteriormente aprobadas por la Asamblea Nacional.

Además, es importante destacar una de las medidas que más ha llamado la atención popular, al permitir la constitución de cooperativas en sectores de producción que no son los agrícolas e industriales. Sus secuelas deberán ser examinadas con atención, pues llegarán a ser un punto nuevo de asociación y agrupación interesante para el desarrollo la sociedad civil.

Asimismo, con varias consultas populares, que iban más allá de la elección única de sus representantes a los organismos de poder, se pretendía hacer partícipe a la población del proceso reformador que sacude el país. Se deduce como un modo idóneo de legitimar las decisiones, si bien su funcionalidad era más bien consultiva y carente de vinculación. Verdaderamente, la naturaleza del sistema político sigue inmutable y sin visos de grandes transformaciones. Ante la aparente apertura hacia la implicación de la sociedad, se esconde la prevención de evitar posibles alteraciones del orden público. Precisamente, las disposiciones de carácter político no levantan grandes expectativas entre los ciudadanos, resignados ante la retórica de unos discursos que anuncian transformaciones, mientras todo permanece más o menos igual (Bayo, 2011). Dicha desafección del pueblo hacia la política y sus dirigentes, sirve de aliciente para acrecentar las oposiciones, a la par de que se universaliza un sentimiento de parsimonia y conformismo.

Definitivamente, si consideramos que en la actualidad se están produciendo avances en el régimen cubano, la política ha sido la pieza menos modificada por el momento. Los debates internos han sido muy tenues, escondidos en la maraña censurar del sistema, alimentado que oficialmente no existan voces discordantes. Por supuesto, las discrepancias externas continúan siendo reprimidas (Human Rights Watch, 2013), no hay lugar a la oposición. Lo que acontece a cambios, estos apenas han rozado la arquitectura política del régimen cubano, el gobierno controla los medios de comunicación y acota el acceso a la información, las posibilidades de concertación política y social están absolutamente supervisadas por control estatal.

Por otra parte, las medidas sociales más relevantes, sin ningún tipo de apelativos, son las que han afectado directamente a las condiciones de jubilación y la regulación de los procesos migratorios. Realmente, como la actividad política, las cuestiones sociales no han supuesto una prioridad para el gobierno cubano, sus preocupaciones giran en torno al crecimiento económico, aunque es indudable que deberán estar precavidos en ciertas disposiciones. No obstante, oficialmente las directrices sociales están presentes, a pesar de perderse en la oratoria típica de los documentos públicos. El mismo Folleto de Lineamientos del VI Congreso Nacional del Partido, donde se recogían las principales conjeturas sobre los programas sociales y económicos, no clarifica en absoluto cuales son los pasos a seguir en esta materia; queriendo preservar los logros alcanzados por la revolución. Más, hay que puntualizar que en dicho documento se anotan algunos anuncios notables no muy explicitados. Entre ellos recalamos en el propósito de disminuir paulatinamente la 
Hernández, David. Reformulando la revolución cubana. La presidencia de Raúl Castro (20082013)

participación de los presupuestos del Estado en el financiamiento de la seguridad social, debido a que se reconoce que continuará creciendo a partir del incremento del número de personas jubiladas, por la evolución demográfica de Cuba. Ídem, en los párrafos 165 y 166 se quiere primar la asistencia social a aquellas personas que realmente lo necesitan, lo que compromete, más temprano que tarde, muchas de las ayudas estatales. También, en otros artículos se menciona la necesidad de incrementar los salarios de manera gradual, siempre vinculándolos a las actividades con los resultados más eficientes, buscando paliar los efectos inflacionistas.

De todos modos, anteriormente expresamos que las dos políticas sociales de mayor envergadura por el momento aplicadas, son la postergación de la edad de jubilación y modernización del ordenamiento para la salida de ciudadanos cubanos. En un apartado pasado, explicamos los problemas demográficos que deben afrontar las autoridades ante una población que se encuentra en pleno proceso de envejecimiento, lo que conlleva a un número cada vez más elevado de personas dependientes, a la par de la consabida disminución del porcentaje de población activa. Por ello, una de las primeras medidas tomadas por el recién elegido presidente fue la aprobación en 2008, con el beneplácito del plenario de la Asamblea Nacional y tras un arduo debate, de una nueva ley de Seguridad Social que atajaba francamente el sistema anterior de pensiones y jubilaciones (Domínguez, 2009 b). Entre otros tecnicismos, directamente la nueva legislación reduciría las nóminas de las pensiones. Por otra parte, hasta entonces se permitía la prejubilación de las mujeres a los 55 años y los hombres a los 60 años, algo que se convirtió en una práctica muy habitual; con la nueva ley imperativamente se extendía cinco años más para ambos sexos.

Concluyentemente, la cuestión migratoria y las posibilidades de viajar al exterior por parte de los cubanos, ha sido dentro de todo el ciclón reformista que ha sacudido el país caribeño, una de las medidas que más ha llamado la atención de los nacionales y extraños. Además, interrelacionado con la problemática demográfica, la emigración supone una auténtica tragedia para la economía cubana, pues representa la pérdida de capital humano, la mayor parte de ellos jóvenes, dentro de una actividad productiva que empieza a escasear de ella (Blanco, 2012). Más aún, las intransigentes políticas sobre el control de entrada y salida, ha impedido el retorno de muchos de ellos; aunque es cierto que gran parte de los isleños que consiguen salir no se plantean a corto plazo volver, incluso muchos de ellos se afincan permanentemente en otros países, principalmente en la costa sureña de los Estados Unidos.

A pesar de ello, la diáspora de ciudadanos no es un fenómeno extraño para el régimen comunista. Prácticamente desde los inicios de la revolución, ésta ha sufrido diferentes etapas, donde los motivos de la marcha han combinado las discrepancias políticas con las expectativas de mejorar condiciones de vida que han ido deteriorándose dentro de la burocracia estatal (Dilla Alfonso, 2012). Con todo ello, las preocupaciones sobre las relaciones con los cubanos que desean partir, así como los que están fueran, se han vuelto transcendentales para el régimen. Es reconocida la importancia para el crecimiento continuado de la economía autóctona las remesas, suponiendo una ayuda financiera para numerosas familias que siguen en Cuba; incluso muchos hogares se han vuelto dependientes de ese dinero. 
Hernández, David. Reformulando la revolución cubana. La presidencia de Raúl Castro (20082013)

Finalmente, tras aletargadas reflexiones internas, se proyectó un programa novedoso calculado y densamente meditado sobre la futura política migratoria. A través de tres decretos y una decena de resoluciones, se modificó por completo la anticuada y obsoleta ley 1.312 de 1976, (Dilla Alfonso, 2012: 71-72). La nueva legislación es una superación de las prohibiciones y limitaciones anteriores, permitiendo la salida y entrada de conciudadanos de una forma mucho más libre. Los cubanos que desean partir del país, ya sea por turismo o razones laborales, podrán hacerlo sin las más dificultades que presenta superar los distintos procesos derivados de la lenta burocracia estancada en la administración pública.

\section{CONCLUSIÓN: ¿EL FIN DE LA REVOLUCIÓN?}

La llegada a la presidencia de Raúl Castro supone ya de por sí una alteración del orden perpetuado durante más de cincuenta años en el poder. Raúl no es Fidel, y esta simple negación implica una gran variedad de efectos dentro y fuera del régimen. No obstante, ha existido un ingenuo cálculo entre distintas corrientes y actores, que creían ver en la retirada de la primera línea del Gran Líder, un halo de esperanza para la democratización del estado comunista. Nada más lejos de la realidad que se ha ido imponiendo con el paso del vigente lustro, donde el hermano pequeño de los Castro ha intentado introducir cambios, algunos nada desechables, en la arquitectura cubana para conseguir preservar, al menos mientras Fidel y él no perezcan, el sistema que los revolucionarios de la Sierra Maestra establecieron en la isla.

Por lo tanto, no es erróneo señalar que desde el ascenso al máximo órgano de poder por parte de Raúl en 2008, en Cuba se están produciendo innumerables cambios que afectan principalmente a la maltrecha economía nacional, aunque también han tenido su resonancia en medidas de carácter social y política. Empero, desde el inicio de esta nueva etapa sin la sombra de Fidel Castro, muchos han visto la plausible llegada de nuevos vientos de cambio a la república socialista caribeña, soñando con encontrarse en el inicio de una etapa transitoria que pudiera enterrar el arcaico modelo imperante.

Sin embargo, más allá de los discursos y los documentos oficiales, alejados de la falsa candidez que transmiten algunos debates internos de partido, los hechos han demostrado que los cambios programados son para transformar el régimen y adaptarlo a las vicisitudes de los tiempos, no para derrocarlo. Más que nunca, en la actualidad cubana se valida la paradoja lampedusiana de cambiar todo para que nada cambie. Es decir, Raúl Castro en absoluto será el hombre que traiga la apertura total del país al mundo y las oportunidades de disensión interna, sus dos reelecciones ante los compañeros de partido de la Asamblea Nacional suponen la reafirmación de que los pilares esenciales del régimen siguen intactos.

Además, como hemos podido comprobar con nuestro análisis, la formulación y aplicación de las reformas de distinta índole, tienen como razón última soslayar las eventualidades más acuciantes, que puedan perjudicar a corto plazo la permanencia del régimen. Ninguna de las políticas emprendidas es imaginada con vistas a largo plazo, responden a la urgencia de atajar las premuras surgidas tanto dentro como fuera, y para las que el estado comunista no estaba preparado. Como ya ocurriera en otros tiempos de dificultades, las salidas encontradas en formas de medidas no 
Hernández, David. Reformulando la revolución cubana. La presidencia de Raúl Castro (20082013)

son irreversibles, nadie puede esperar que lo entendido como avances no sea pronto revocado; meros parches temporales para solventar las incertidumbres generadas.

Este cuadro pesimista sobre las reformas gubernamentales se transmite en la propias renovaciones de las cúpulas de poder, donde si analizamos las características de los nuevos dirigentes veremos que no hay expectativas de verdaderos cambios. Raúl Castro sigue rodeado de aquellos que han acompañado tanto a él como su hermano a los mandos de la isla, siendo extremadamente recelosos de ceder autoridad a sujetos críticos o desconfiados de su fidelidad al statu quo castrista. Todo ello, ha dificultado que desde dentro del partido y las fuerzas revolucionarias se pudieran dar renovaciones generacionales que indujeran al cambio, más aún, esa actitud intransigente provoca que los más jóvenes deban limitarse estrictamente a los contornos señalados.

De este modo, la transformación que pudiera acontecer desde el corazón mismo del estado cubano, se reduce a unas reformas absolutamente programas y calculadas, que intentan buscar la adaptabilidad del sistema a los tiempos actuales, sin que ello suponga el peligro de generar una demolición descontrolada.

Por otra parte, en la última Asamblea Nacional celebrada en el mes de febrero de 2013, Raúl Castro anunciaba a los medios de comunicación su intención de no prolongar su presencia en el poder más allá de 2018. Ante esta noticia se abren multitud de inquietudes, principalmente los centrados en conocer cuál podría ser el sucesor de los hermanos Castro. Aunque, recién acaba de empezar su segundo mandato, las especulaciones sobre el futuro del país caribeño tras la desaparición de los dos hermanos. Si bien es cierto, que mientras Fidel y Raúl sigan haciendo acto de presencia en la vida política, el régimen constituido por ellos mismos no dará avisos de acabarse; los interrogantes se ciernen tras su más que probable ausencia.

El modelo político edificado durante gran parte del siglo $X X$, ha sido una muestra de un arquetipo absolutamente personalista, por lo que es inevitable preguntarse qué destino espera a Cuba tras los Castro, una pregunta que ahora mismo nadie se atreve a responder con certeza. Lo que sí parece meridianamente claro es que mientras Raúl siga ostentando el poder, incluso estando su hermano apartado de toda actividad, la dirección nacional estará encaminada a mantener el régimen. Ahora bien, como bajo el liderazgo de Fidel Castro las capacidades de mando en la isla se concentraron en unas pocas manos, su progresiva retirada de los principales protagonistas de los cuadros de poder, aunado al completo desinterés por parte del propio sistema por realizar una restitución generacional; abocará al régimen seguramente a una situación arduamente complicada, al difuminarse el último dirigente.

Decididamente, la llegada de la democracia y el decaimiento del autoritarismo, tendrán que esperar, como mínimo, a que desaparezcan las figuras de los hermanos Castro. En ese mismo instante, nos situaremos en un panorama desconocido e impredecible, complicado vaticinar las crisis que se iniciaran en Cuba. Pero hasta entonces, las expectativas generadas por la coyuntura reformista protagonizada por la presidencia de Raúl, no irán más allá de la sostenibilidad de la histórica revolución. 
Hernández, David. Reformulando la revolución cubana. La presidencia de Raúl Castro (20082013)

\section{BIBLIOGRAFÍA}

Alonso, J, A; Bayo, F. et al (2011). Cuba en tiempos de cambios. Madrid, Editorial Complutense D, L.

Alzugaray, C. (2012). "Las relaciones inexistentes Cuba-Estados Unidos en tiempos de cambio" en Nueva Sociedad. № 242, noviembre-diciembre 2012, pp. 140148.

Alzugaray, C. (2009). "Cuba: cincuenta años después: continuidad y cambio político" en Revista Temas. № 60, octubre-diciembre 2009, pp. 37-47.

Amor, E. (2010) Economía cubana: la oportunidad perdida. Valencia, Aduana Vieja.

Balfour, S. (2009). Fidel Castro: una biografía política. Barcelona, Península.

Bayo, F. (2011). "EI VI Congreso del PC cubano confirma la política de adaptación de Raúl Castro" en Opinión CIDOB. № 114, 27 de abril de 2011.

Bayo, F (2010). "Diálogo en Cuba y con Cuba" en Opinión CIDOB. № 79, 13 de junio de 2010.

Blanco, J. A. (2012). "Cuba en el siglo XXI: escenarios actuales, cambios inevitables, futuros posibles" en Nueva Sociedad. № 242, noviembre-diciembre 2012.

Botín, V. (2010): Raúl Castro: la pulga que cabalgó al tigre. Barcelona, Ariel.

Campos, J. C. (2013). "Transición y sociedad en la Cuba actual" en Revista Temas. 22 de febrero de 2013. Intervención en el panel "Problemas de la transición socialista en Cuba" 22a Feria Internacional del Libro de La Habana.

CEPAL (2012). Informe macroeconómico 2011-2012. CEPAL. CUBA 2012.

CEPAL (2004). Política social y reformas estructurales: Cuba a principios del siglo $X X I$. México, CEPAL.

Cordoví, J. T. (2012). "Cuba ¿de la "actualización" del modelo económico al desarrollo? en Nueva Sociedad. №242 noviembre-diciembre 2012.

Díaz-Vázquez, J. A. (2010). "Cuba-China: 50 años de vínculos económicos" en Observatorio Virtual Asia Pacífico. www.utadeo.edu.co (visitado 24 de abril de 2012).

Díaz-Vázquez, J. A. (2008). "Apuntes sobre las relaciones China-Cuba" en Observatorio de la Economía y la Sociedad de China № 09, diciembre 2008. www.igadi.org (visitado 24 de abril de 2012).

Dilla Alfonso, H. (2012). "Las encrucijadas de la política migratoria cubana" en Nueva Sociedad. № 242, pp 70-81. noviembre-diciembre, 2012.

Dilla Alfonso, H (2008). "La dirección y los límites de los cambios" en Nueva Sociedad. № 216, pp 36-48. julio-agosto 2008.

Domínguez, J. I. (2009a). La política exterior de Cuba (1962-2009). Madrid, Colibrí.

Domínguez, J. I. (2009b). "Raúl Castro: 50 años en el poder" en Comentarios FRIDE. 14 de enero de 2009.

Everleny, O. (2011). Cuba: evolución económica reciente. Informe de Centro de Estudios de la Economía Cubana. Universidad de La Habana.

Everleny, O. (2010a). "Notas recientes sobre la economía en Cuba" conferencia dictada durante la X Semana Social Católica. La Habana, del 16 al 20 de junio de 2010.

Everleny, O. (2010b). "Cuba: ¿por dónde va la economía? en Revista Temas. 9 de abril de 2010. www.temas.cult.cu (visitado 26 de marzo de 2013)

Everleny, O. (2008). "La economía en Cuba: un balance necesario y algunas propuestas de cambio" en Nueva Sociedad. № 216, pp 49-64. Agosto de 2008.

Garrido, V.; Isbell, P. A. et al (2009.: Venezuela y la revolución bolivariana. Instituto Universitario Gutiérrez Mellado. Madrid 2009. 
Hernández, David. Reformulando la revolución cubana. La presidencia de Raúl Castro (20082013)

Gamboa, F. (2009). "Cincuenta años de la revolución cubana: del mito al futuro incierto" en Nómadas. Vol.21, pp 21-40. №1. 2009.

Gortázar, G. (2012). Cuba: camino de libertad: discursos, textos y documentos, 1990-2012. Fundación Hispano-Cubana.

Gratius, S. (2008a). "Cuba: el legado de la revolución" en Comentarios FRIDE. 19 de diciembre de 2008.

Gratius, S. (2008b). "Cuba: entre continuidad y cambio" en Comentarios FRIDE. 9 de marzo de 2008.

Human Rights Watch (2013). Informe Mundial: Cuba. Capítulo del Informe Mundial reservado a Cuba 2012.

Human Rights Watch (2009). Un nuevo Castro, la misma Cuba: presos políticos en la era post Fidel. Human Right Watch. 2009.

ICEX (2012). Informe económico y comercial. Cuba 2012. La Oficina Económica y Comercial de España en La Habana Actualizado a julio 2012

Mesa-Lago, C. (2011). "Las reformas de Raúl Castro y el congreso del Partido Comunista de Cuba: avances, obstáculos y resultados" en Documentos CIDOB. № 35. Noviembre de 2011.

Mesa-Lago, C. (2010). "El desempleo en Cuba: de oculto a visible" en Espacio Laical. № 4, 2010.

Montaner, C. A. (2009). "Fidel Castro y su extraña familia" en $A B C .1$ de noviembre de 2009.

ONEI (2012). Anuario Estadístico de Cuba 2011. Oficina de Estadística e Información de la República de Cuba. Edición 2012.

ONEI (2009). "Caracterización sociodemográfica de los jóvenes cubanos" en Cuadernos de Estudio y Población. № 2, Edición 2009.

Padura-Fuentes, L- (2012). "Eppur si muove en Cuba" en Nueva Sociedad. № 242, noviembre-diciembre 2012.

Partido Comunista Cubano (2011). Lineamientos de la política económica y social del partido y la revolución. VI Congreso del Partido Comunista Cubano.

Pavel Vidal, A. (2011). "Desarticular el monopolio de la centralización estatal" entrevista en Espacio Laical. № 123. Febrero 2011.

Pavel Vidal, A. (2008). "Política monetaria en Cuba. Estimación con un modelo VAR estructural" en Revista Principios. Diciembre de 2008.

Rico, M. (2009). "Raúl Castro mantiene intacta la represión en Cuba" en El País. 18 de noviembre de 2009.

Rivera, R. (2013). "Gorbachov no usa guayaberas" en La Aventura de la Historia. Año15, № 175, pp 10-11. 2013.

Rojas, R. (2013). “¿Reforma política en Cuba?” en El País. 28 de febrero de 2013.

Romero, Carlos A. (2006). Jugando con el globo. La política exterior de Hugo Chávez. Caracas, Ediciones B.

Sánchez, Y. (2010). Cuba libre: vivir y escribir en La Habana. Barcelona, Debate.

Serbin, A. (2013). "La política exterior de Cuba en un mundo multipolar" en Mesa, M (coord.), Cambio de ciclos: crisis, resistencias y respuestas globales. Anuario 2012-2013. CEIPAZ, Madrid, Fundación Cultura de Paz.

Serbin, A. (2012). "Regionalismo y soberanía nacional en América Latina: lecciones aprendidas y nuevos desafíos" en Mesa, M (coord.) El mundo a la deriva: crisis y pugnas de poder. Anuario 2011-2012. CEIPAZ, Madrid, Fundación Cultura de Paz.

Skierka, V. (2007). Fidel Castro, la biografía definitiva del líder cubano. Madrid, Ediciones Martínez Roca S.A. 
Hernández, David. Reformulando la revolución cubana. La presidencia de Raúl Castro (20082013)

Vicent, M. (2013). "Cuba y Venezuela, dos países unidos por el socialismo" en El País Internacional. Madrid 6 de marzo de 2013.

Vicent, M. (2011). "Cuba y China consolidan su alianza estratégica" en El País Internacional. La Habana 8 de junio de 2011.

Vicent, M. (2010). "Entrevista a Guillermo Fariñas" en El País Internacional. Santa Clara 2 de marzo de 2010.

Vinogradoff, L. (2013). "La relación Cuba-Venezuela, en cuidados intensivos" en $A B C$. Caracas 16 de enero de 2013.

Ubieta Gómez, E. (2012). Cuba: ¿revolución o reforma? La Habana, Abril.

\section{Páginas Web}

www.one.cu Página Oficial de la Oficina Nacional de Estadística e Información www.unicef.org Fondo de Naciones Unidas para la Infancia (UNICEF)

www.hdrstats.undp.org Página Oficial del Índice de Desarrollo Humano del Programa de Naciones Unidas para el Desarrollo (PNUD) 